\title{
Measurement of tumour size with mammography, sonography and magnetic resonance imaging as compared to histological tumour size in primary breast cancer
}

Ines V Gruber ${ }^{1}$, Miriam Rueckert ${ }^{1}$, Karl O Kagan ${ }^{1}$, Annette Staebler ${ }^{2}$, Katja C Siegmann $^{3}$, Andreas Hartkopf ${ }^{1}$, Diethelm Wallwiener ${ }^{1}$ and Markus Hahn ${ }^{1 *}$

\begin{abstract}
Background: Tumour size in breast cancer influences therapeutic decisions. The purpose of this study was to evaluate sizing of primary breast cancer using mammography, sonography and magnetic resonance imaging (MRI) and thereby establish which imaging method most accurately corresponds with the size of the histological result.

Methods: Data from 121 patients with primary breast cancer were analysed in a retrospective study. The results were divided into the groups "ductal carcinoma in situ (DCIS)", invasive ductal carcinoma (IDC) + ductal carcinoma in situ (DCIS)", "invasive ductal carcinoma (IDC)", "invasive lobular carcinoma (ILC)" and "other tumours" (tubular, medullary, mucinous and papillary breast cancer). The largest tumour diameter was chosen as the sizing reference in each case. Bland-Altman analysis was used to determine to what extent the imaging tumour size correlated with the histopathological tumour sizes.

Results: Tumour size was found to be significantly underestimated with sonography, especially for the tumour groups IDC + DCIS, IDC and ILC. The greatest difference between sonographic sizing and actual histological tumour size was found with invasive lobular breast cancer. There was no significant difference between mammographic and histological sizing. MRI overestimated non-significantly the tumour size and is superior to the other imaging techniques in sizing of IDC + DCIS and ILC.
\end{abstract}

Conclusions: The histological subtype should be included in imaging interpretation for planning surgery in order to estimate the histological tumour size as accurately as possible.

Keywords: Breast cancer, Tumour size, Sonography, Mammography, Magnetic resonance imaging, Ductal carcinoma in situ, Invasive ductal carcinoma, Invasive lobular carcinoma

\section{Background}

The key importance of imaging methods in breast diagnostics lies in the detection and sizing of areas suspicious for malignancy. Breast results are classified using the BI-RADS (Breast Imaging Reporting and Data System) classification $[1,2]$.

Exact pre-therapeutic tumour sizing using imaging methods plays a central role. For example, the possibility

\footnotetext{
* Correspondence: Markus.Hahn@med.uni-tuebingen.de

'Department of Obstetrics and Gynecology, University Hospital of Tuebingen, Calwer Street 7, 72076, Tuebingen, Germany

Full list of author information is available at the end of the article
}

of breast conserving treatment significantly depends on the relationship between the tumour-to-breast size. Furthermore, the indication for primary systemic treatment is made, amongst other things, from the tumour size.

The aim of this study was to analyse which of the given imaging methods is the most accurate in the pretherapeutic sizing of primary breast cancer.

\section{Methods}

121 patients with primary breast cancer who presented preoperatively in the University Breast Centre of Tuebingen between June 2005 and July 2007 were

\section{Biomed Central}


retrospectively analysed. All patients fulfilled the following criteria: primary breast cancer, no neoadjuvant chemotherapy, complete documentation of the tumour size from mammography, sonography and magnetic resonance imaging (MRI) as well as the postoperative histological tumour size. The largest tumour diameter was chosen as the sizing reference in each case.

\section{Diagnostic imaging equipment}

Mammography was performed using two digital full field instruments (Senographe 2000 D, GE Healthcare, Munich, Germany; Selenia, Hologic GmbH, Frankfurt am Main, Germany).

Sonography was performed using a linear transducer with a $50 \mathrm{~mm}$ width and a frequency of $12 \mathrm{MHz}$. Models iU22 and HD 11 from Philips (Philips GmbH Healthcare, Hamburg, Germany) were used. The examination was carried out using "Spatial Compound Imaging" and "XRES Adaptive Image Processing". Measurement of tumor size took the echopoor centre of the lesion and the echogenic halo into account. The clinical examiner held a minimum of the Degum Level 2 qualification.

Magnetic resonance imaging (MRI) was performed using a 1.5 Telsa system (Gyroscan Achieva, Philips GmbH Healthcare, Hamburg, Germany). A T1-weighted dynamic gradient echo sequence $(\mathrm{T} 1 \mathrm{w}-\mathrm{FFE}=$ Fast Field Echo) with a native and 7 post-contrast medium series was used. Automated bolus injection of $0.16 \mathrm{mmmol}$ Gadobutrol per kg body weight followed by $10 \mathrm{ml}$ saline were infused intravenously. Image post-processing included the generation of subtraction series and reconstruction of a MIP (maximum intensity projection). Imaging analysis was carried out using the digital data with the help of a suitable workstation (View Forum, Philips Healthcare, Hamburg, Germany).

Only physicians who were specialized on breast diagnostics performed and reviewed each imaging.

\section{Statististical evaluation}

The histological results were divided into the groups "ductal carcinoma in situ (DCIS)", "invasive ductal carcinoma (IDC) + ductal carcinoma in situ (DCIS)", "invasive ductal carcinoma (IDC)", "invasive lobular carcinoma (ILC)" and "other tumours" (tubular, medullary, mucinous und papillary breast cancer). The largest tumour diameter was chosen as the sizing reference in each case. Bland-Altman analysis was used to determine to what extent the imaging tumour size correlated with the histopathological tumour sizes.The mean difference between the imaging and the histological results was calculated and related to the interval in which $95 \%$ of the calculated differences were found (LOA $=$ limits of agreement). Size variation on imaging versus pathology were reported as median and interquartile range, using
Box plots. The statistical analysis was performed using SPSS $^{\circ}$ for Windows (Version 15.0; IBM, Chicago). The level of significance was defined as a p-value of $<0.05$.

There was no objection against the study from the local ethic committee.

\section{Results \\ Patient collective and malignancy assessment using imaging}

121 patients with primary breast cancer were evaluated in a retrospective analysis. The median age was 57 years (range 35-92). An IDC was present in 33.9\% of the cases. $31.4 \%$ of the patients were allocated to the IDC + DCIS tumour group, and a DCIS alone or ILC alone were found in $12.4 \%$ and $14.9 \%$ respectively. "Other tumours" occurred in $7.4 \%$ of the cases.

The density level of the breast tissue was graded using mammography according to the American College of Radiology (ACR) [1] classification system. In doing so, 8.3\% exhibited predominantly lipomatous glandular tissue (ACR I). A mammographic density grade II was present in $29.8 \%$ and a density grade III in $47.9 \%$. $13.2 \%$ of women had very dense glandular tissue (ACR IV). Density grading was not carried out in one case $(0.8 \%)$. Malignancy assessment using imaging was performed according to the BI-RADS classification system [1], whereby $96.6 \%$ of the sonographic results, $90.9 \%$ of the mammography results and $100 \%$ of the MRI results were pre-interventionally classified as BI-RADS 4 or higher (Table 1).

\section{Comparison of histological sizing with the sizing indication from sonography, mammography and MRI}

As demonstrated in Table 2, there was a mean difference between the sonographic and histological sizing of $-8 \mathrm{~mm}$ (LOA: -43 to $28 \mathrm{~mm}$ ). The median difference was $-2 \mathrm{~mm}$ (interquartile range: -10 to $1 \mathrm{~mm}$, Figure 1 ). In the total sonographic collective, there was a highly significant underestimation of tumour size (Table 2), which can be particularly seen in histologically larger lesions (Figure 2). Based on the individual tumour groups, a significant underestimation of size was detected for IDC + DCIS, IDC and ILC (Table 2).

The mean difference between mammography and histology was $-1 \mathrm{~mm}$ (LOA: -36 to $34 \mathrm{~mm}$, Table 2). The median difference was $0 \mathrm{~mm}$ (interquartile range: -5 to $4 \mathrm{~mm}$, Figure 1). There was a non-significant underestimation of size in the whole collective (Figure 3) with no significance based on the individual tumour groups (Table 2).

Using MRI, the mean difference in sizing, as compared to the histological tumour size, was found to be $2 \mathrm{~mm}$ (LOA: -34 to $39 \mathrm{~mm}$, Table 2). The median difference was $2 \mathrm{~mm}$ (interquartile range: -1 to $7 \mathrm{~mm}$, Figure 1), which corresponded with a non-significant size overestimation in 
Table 1 Correlation between the BI-RADS classification (Breast Imaging Reporting and Data System) and the histology for the corresponding imaging method

\begin{tabular}{|c|c|c|c|c|c|c|c|}
\hline Diagnostic imaging & BI-RADS classification & $\begin{array}{c}\text { Isolated DCIS } \\
\mathrm{N}(\%) \\
\end{array}$ & $\begin{array}{c}\text { IDC-DCIS } \\
\text { N (\%) }\end{array}$ & $\begin{array}{c}\text { Isolated-IDC } \\
\mathrm{N}(\%)\end{array}$ & $\begin{array}{c}\text { Isolated ILC } \\
\mathrm{N}(\%) \\
\end{array}$ & $\begin{array}{c}\text { Other tumours } \\
\mathrm{N}(\%)\end{array}$ & $\begin{array}{l}\text { Total } \\
\mathrm{N}(\%) \\
\end{array}$ \\
\hline \multirow[t]{7}{*}{ Sonography } & 0 & $0(0 \%)$ & $0(0 \%)$ & $0(0 \%)$ & $0(0 \%)$ & $0(0 \%)$ & $0(0 \%)$ \\
\hline & 1 & $0(0 \%)$ & $0(0 \%)$ & $0(0 \%)$ & $0(0 \%)$ & $0(0 \%)$ & $0(0 \%)$ \\
\hline & 2 & $0(0 \%)$ & $0(0 \%)$ & $0(\%)$ & $0(0 \%)$ & $1(11.1 \%)$ & $1(0.8 \%)$ \\
\hline & 3 & $0(0 \%)$ & $0(0 \%)$ & $3(7.3 \%)$ & $0(0 \%)$ & $0(0 \%)$ & $3(2.5 \%)$ \\
\hline & 4 & $10(66.7 \%)$ & $17(44.8 \%)$ & $10(24.4 \%)$ & $8(44.4 \%)$ & $5(55.6 \%)$ & $50(41.3 \%)$ \\
\hline & 5 & $5(33.3 \%)$ & $20(52.6 \%)$ & $28(68.3 \%)$ & $10(55.6 \%)$ & $3(33.3 \%)$ & $66(54.5 \%)$ \\
\hline & 6 & $0(0 \%)$ & $1(2.6 \%)$ & $0(0 \%)$ & $0(0 \%)$ & $0(0 \%)$ & $1(0.8 \%)$ \\
\hline \multirow[t]{7}{*}{ Mammography } & 0 & $0(0 \%)$ & $1(2.6 \%)$ & $0(0 \%)$ & $1(5.6 \%)$ & $0(0 \%)$ & $2(1.7 \%)$ \\
\hline & 1 & $0(0 \%)$ & $0(0 \%)$ & $0(0 \%)$ & $0(0 \%)$ & $0(0 \%)$ & $0(0 \%)$ \\
\hline & 2 & $0(0 \%)$ & $0(0 \%)$ & $0(0 \%)$ & $0(0 \%)$ & $0(0 \%)$ & $0(0 \%)$ \\
\hline & 3 & $1(6.7 \%)$ & $4(10.5 \%)$ & $3(7.3 \%)$ & $0(0 \%)$ & $1(11.1 \%)$ & $9(7.4 \%)$ \\
\hline & 4 & $1(6.7 \%)$ & $12(31.6 \%)$ & 17 (41.5\%) & 11 (61.1\%) & $5(55.6 \%)$ & 46 (38.0\%) \\
\hline & 5 & 13 (86.6\%) & 19 (50\%) & $17(41.5)$ & 6 (33.3\%) & $3(33.3 \%)$ & 58 (47.9\%) \\
\hline & 6 & $0(0 \%)$ & $2(5.3 \%)$ & $4(9.7 \%)$ & $0(0 \%)$ & $0(0 \%)$ & $6(5.0 \%)$ \\
\hline \multirow[t]{7}{*}{ MRI } & 0 & $0(0 \%)$ & $0(0 \%)$ & $0(0 \%)$ & $0(0 \%)$ & $0(0 \%)$ & $0(0 \%)$ \\
\hline & 1 & $0(0 \%)$ & $0(0 \%)$ & $0(0 \%)$ & $0(0 \%)$ & $0(0 \%)$ & $0(0 \%)$ \\
\hline & 2 & $0(0 \%)$ & $0(0 \%)$ & $0(0 \%)$ & $0(0 \%)$ & $0(0 \%)$ & $0(0 \%)$ \\
\hline & 3 & $0(0 \%)$ & $0(0 \%)$ & $0(0 \%)$ & $0(\%)$ & $0(0 \%)$ & $0(0 \%)$ \\
\hline & 4 & $0(0 \%)$ & $2(5.3 \%)$ & $4(9.8 \%)$ & $0(0 \%)$ & $0(0 \%)$ & 7 (5.8\%) \\
\hline & 5 & $9(60 \%)$ & $22(57.9 \%)$ & $26(63.4 \%)$ & $8(44.4 \%)$ & $3(33.3 \%)$ & $68(56.2 \%)$ \\
\hline & 6 & $6(40 \%)$ & $14(36.8 \%)$ & $11(26.8 \%)$ & $9(50 \%)$ & $6(66.7 \%)$ & 46 (38.0\%) \\
\hline
\end{tabular}

DCIS Ductal carcinoma in situ, IDC Invasive ductal carcinoma, ILC Invasive lobular carcinoma.

the whole collective (Figure 4). No significant correlations were found within the individual tumour groups (Table 2).

\section{Discussion}

Breast lesion sizing by ultrasound imaging, mammography and MRI in comparison to histopathological sizing This retrospective analysis showed a highly significant underestimation of the mean histological tumour size with sonography (Table $2 ; \mathrm{p}<0,001$ ), with a mean of $8 \mathrm{~mm}$. This underestimation increased as the histological result size increased (Figure 2). The investigations by Hieken et al. [3], Shoma et al. [4] and Bosch et al. [5] confirmed the sonographic underestimation of the histological tumour size. Hieken et al. [3] attributed this to the unclear margins of sonographic results from extensive intraductal in-situ components. Bosch et al. [5] linked the underestimation with tumour size, with the

Table 2 Comparison of the imaging size and the histological tumour size

\begin{tabular}{|c|c|c|c|c|c|c|c|c|c|}
\hline \multirow{3}{*}{$\begin{array}{l}\text { Tumour } \\
\text { group }\end{array}$} & \multicolumn{9}{|c|}{ Difference between } \\
\hline & \multicolumn{3}{|c|}{ Sonography and histology } & \multicolumn{3}{|c|}{ Mammography and histology } & \multicolumn{3}{|c|}{ MRI and histology } \\
\hline & $M(\mathrm{~mm})$ & LOA (mm) & $r$ & $M(\mathrm{~mm})$ & LOA $(\mathrm{mm})$ & $r$ & $M(\mathrm{~mm})$ & LOA (mm) & $r$ \\
\hline$\overline{\mathrm{DCIS}}$ & -15 & -87 to 56 & 0,304 & -1 & -71 to 68 & 0,374 & 5 & -46 to 56 & 0,744 \\
\hline IDC - DCIS & $-9^{*}$ & -47 to 30 & 0,570 & -4 & -43 to 35 & 0,502 & 2 & -46 to 49 & 0,311 \\
\hline IDC & $-4^{*}$ & -20 to 13 & 0,853 & 3 & -16 to 22 & 0,821 & 3 & -19 to 26 & 0,732 \\
\hline ILC & $-10^{* *}$ & -31 to 11 & 0,853 & 1 & -20 to 13 & 0,821 & 2 & -31 to 34 & 0,732 \\
\hline Other tumours & -1 & -9 to 6 & 0,907 & 3 & -8 to 14 & 0,867 & -2 & -14 to 10 & 0,752 \\
\hline TOTAL & $-8^{* *}$ & -43 to 28 & 0,525 & -1 & -36 to 34 & 0,550 & 2 & -34 to 39 & 0,554 \\
\hline
\end{tabular}

Significant differences ${ }^{*} \mathrm{p}<0,05 * * \mathrm{p}<0,001$.

DCIS Ductal carcinoma in situ, IDC Invasive ductal carcinoma, ILC Invasive lobular carcinoma, M mean, LOA limits of agreement, $r$ - correlation coefficient. 


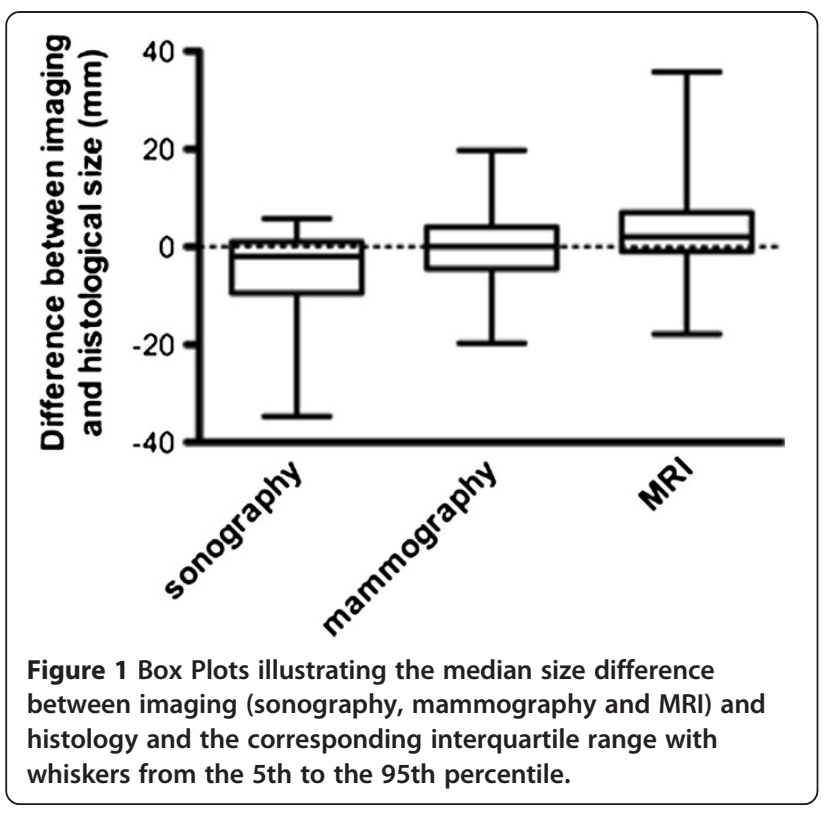

image presentation exceeding what is possible with the transducer. An alternative technique here would be the panorama mode. This technique allows a complete image to be built from individual sectional sonographic images. The sonographic measurement of masses whose diameters exceed the width of the transducer is thereby made more accurate.

With regard to mammography, our data also show an underestimation of the mean histological result of
$1 \mathrm{~mm}$, although this was not found to be significant (Table 2). The study by Hieken et al. [3] also showed a size underestimation with mammography, which was attributed to the high compression of the breast during the examination. Furthermore, the mammographic size estimation is also negatively affected by breast density.

A non-significant size overestimation of $2 \mathrm{~mm}$ in the whole collective was found according to our analysis of the MRI results (Table 2). Onesti et al. [6] described a significant MRI mean overestimation of $1.06 \mathrm{~cm}$, especially for results of $>2 \mathrm{~cm}$ in size. This can be traced back to tumours with larger DCIS-components or a higher proportion of fibrotic tissue.

Studies which comparatively analysed the diagnostic measurement accuracy of mammography, sonography and MRI came to the conclusion that MRI offered the best correlation with the histological tumour size [7-9]. For a mean histological tumour size of $2.76 \mathrm{~cm}$, Wasif et al. [7] identified a mean tumour site of $2.1 \mathrm{~cm}$ using mammography, $1.73 \mathrm{~cm}$ using sonography and $2.65 \mathrm{~cm}$ with MRI. In a study by Boetes et al. [9] the tumour size with mammography and sonography was underestimated in $14 \%$ and $18 \%$ of the results respectively, whereas MRI did not show any significant deviation from the histological sizing.

Significant underestimation of the histological sizing with ultrasound depending on the tumour type

Out data showed a significant underestimation of the histological size with ultrasound with regard to the

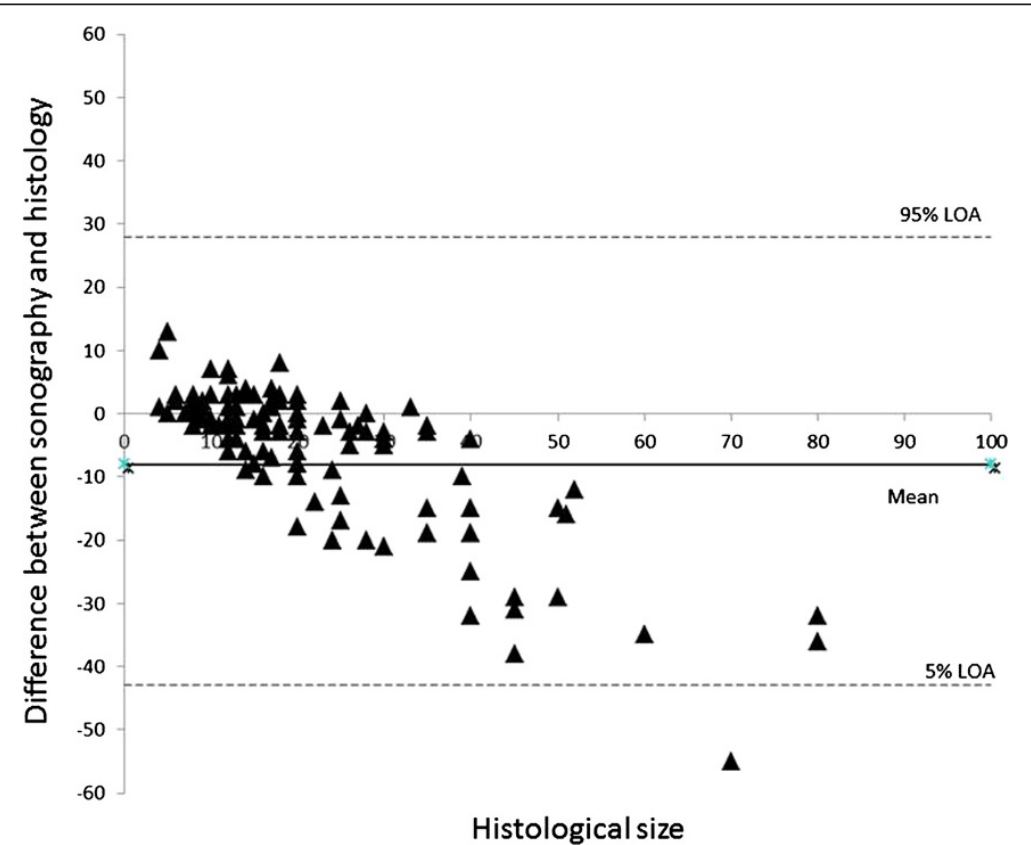

Figure 2 Bland Altman Plots illustrating the size difference between sonography and histology compared to the histological tumour size. 


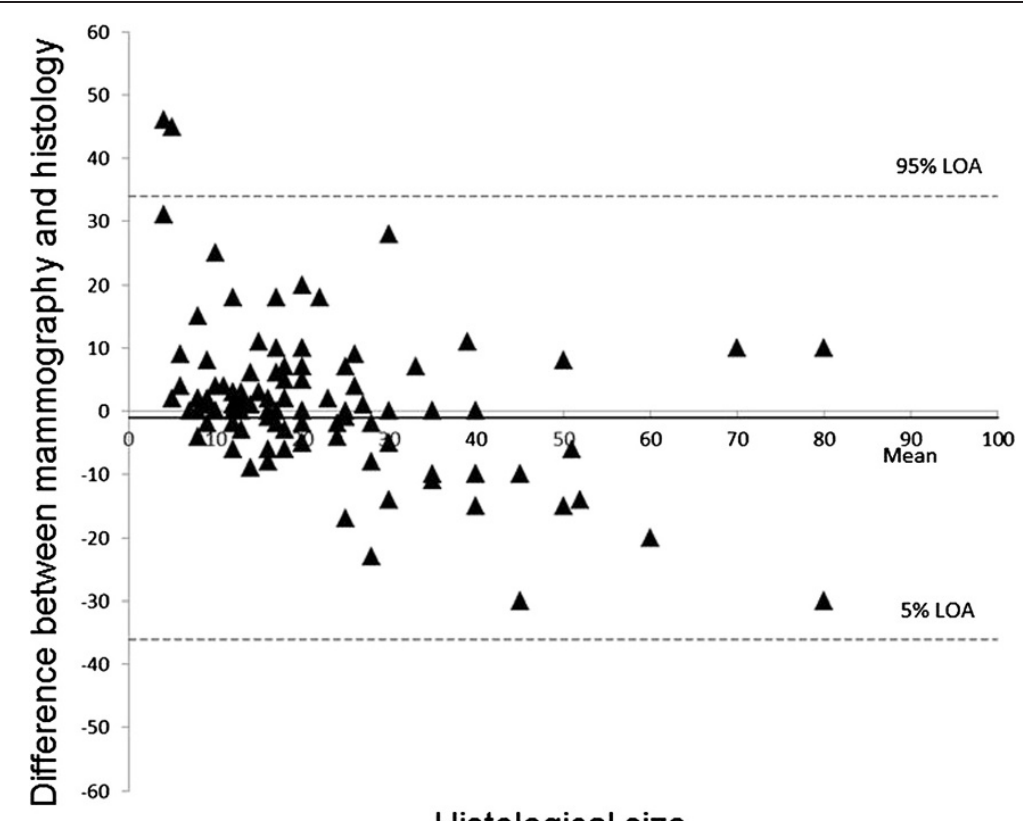

Histological size

Figure 3 Bland Altman Plots illustrating the size difference between mammography and histology compared to the histological tumour size.

tumour groups IDC-DCIS ( $\mathrm{p}=0.008)$, IDC $(\mathrm{p}=0.008)$ and ILC $(p=0.001)$. The greatest mean difference between the sonographically measured tumour size and the actual histological tumour size was found for invasive lobular breast cancer (Table 2). Pritt et al. [10] also described the greatest sonographic size underestimation for ILC compared to IDC or ILC-IDC, with a median of $7.5 \mathrm{~mm}$. Our analysis gave a mean size underestimation of $10 \mathrm{~mm}$ in this group. Diagnostic demarcation of the tumour using imaging is made more difficult because of the diffuse, infiltrative growth pattern of ILC [11]. Furthermore, ILC tends towards multifocality because of

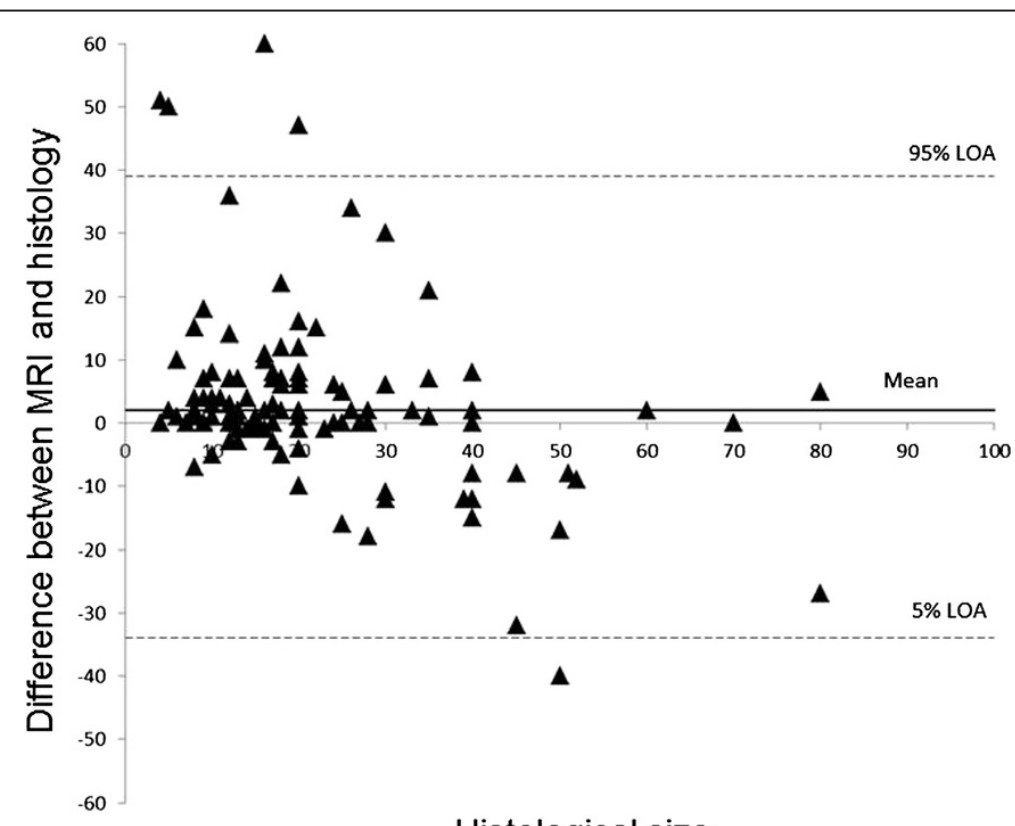

Histological size

Figure 4 Bland Altman Plots illustrating the size difference between MRI and histology compared to the histological tumour size. 
the formation of peritumoral satellite foci, and the additional use of MRI for surgical planning is justifiable, as shown by Rodenko GN et al. [12].

No significant differences between tumour types and histologically established tumour sizes could be found in our study for mammography and for MRI.

\section{Influencing factors of imaging}

In contrast to sonography and MRI, the sensitivity of mammography is significantly negatively affected by increasing breast tissue density [13-15]. Mammographic sensitivity is therefore $30-48 \%$ for ACR IV dense glandular breast tissue [13,15], and mostly breast cancer can only be inadequately displayed with this technique (occult). Breast density also influences the exact sizing of tumours. According to the inclusion criteria definition of our study, results were only included which were visible by all three imaging techniques (mammography, sonography and MRI). Overall, there were no significant variations from the histological tumour size for mammography (Table 2).

If imaging malignancy assessment with reference to the individual tumour groups is considered, isolated DCIS is clearly more commonly classified as BIRADS 5 (Table 1) with mammography (86.8\%) than with sonography $(33.3 \%)$ in our analysis, despite predominantly occurring (66.6\%) in ACR III-IV density glandular breast tissue. This is due to the fact that DCIS is accompanied by typical suspicious microcalcification in $73-98 \%$, which can be identified mammographically independently of the density of the glandular breast tissue [16-18]. Microcalcification is inadequately seen with ultrasound [19-21]. Soo et al. [21] demonstrated that sonographically conspicious lesions were only detected in $23 \%$ of mammographically conspicious microcalcificatons. An exact measurement of the extent of microcalcification is not possible with sonography.

When considering ILC, the detection of clinical findings must be regarded as separate from sizing. In a study by Butler et al. [22], 39\% of the mammographically occult ILC and $88 \%$ of ILC were diagnosed using ultrasound. In our assessment, ILC was present in $14.9 \%$ of all tumours. ILC was diagnosed as BI-RADS 5 in 55\% with sonography and as BI-RADS 5 in $33.3 \%$ using mammography. Ultrasound therefore appears to be superior to mammography in the detection of ILC, whereas mammography can more accurately determine the size than ultrasound.

Sizing of ILC using sonography reveals a significant underestimation of tumour size compared to mammography (Table 2). In this context, a sonographic influencing factor can be the varying individual interpretation of the malignancy criteria by the various clinicians. For example, the clinical finding size varies depending on whether the hyperechoic margin of a tumour is included or not. In a retrospective analysis, it is always important to question whether all clinicians have interpreted the malignancy criteria in the same way $[23,24]$. Further malignancy criteria which could result in differing interpretation of the tumour size are the dorsal acoustic attenuation, the blurred margin and as well as infiltration of the vessels in Doppler sonography [25,26]. Although sonoelastography presents with a lower interobserver variability than conventinal B-mode imaging, Isermann et al. [27] found no significant advantage in breast lesion sizing of this technique.

Modern ultrasound equipment also usually operates with complex image processing software. A danger of the image processing is that clinical findings are modified or so embellished that the interpretation of the classical malignancy criteria done up to now is no longer possible [28]. This could also lead to anomalies in the sizing of focal findings.

In contrast to mammography and sonography, all tumours were correctly preoperatively classified as requiring further clarification (> BI-RADS IV) with MRI, (Table 1), and $38 \%$ of cases were already histologically confirmed (BI-RADS 6). With regard to sizing, there is a non-significant overestimation of size with MRI in all tumour groups. Analogous to our data, other studies [29-32] show that MRI is superior to both mammography and sonography in the diagnosis of DCIS and ILC. In a study by Kuhl et al. [30], MRI showed sensitivity for all DCIS cases, whether with or without microcalcification, of $98 \%$. For mammography, which relies on the interpretation of suspicious microcalcification and therefore does not detect all DCIS cases, the sensitivity was only $52 \%$ [30]. Berg et al. [29] could also show that MRI exhibited a sensitivity of $89 \%$ compared to $55 \%$ sensitivity for mammography and $47 \%$ for ultrasound.

\section{Study limitations}

Investigator influence during the malignancy assessment of the results due to previous knowledge of the results of other imaging techniques cannot be excluded. $38 \%$ of the MRI results were BI-RADS 6-lesions and were therefore histologically confirmed first of all. However, this study considered sizing and not malignancy assessment; therefore this does not appear to have any influence on the results. Moreover study population was retrospectively analysed and limited to only those patients with cancer visible on all three imaging modalities.

\section{Conclusions}

According the data from this study (see Table 2), the following points should be observed for the implementation of valid breast cancer sizing: 
1. IDC can be measured well with all three imaging methods; MRI and mammography are the more exact methods, whilst sonography showed a significant underestimation of the results.

2. IDC with extensive DCIS involvement can be most accurately measured with MRI. Ultrasound leads to a significant size underestimation on average.

3. According to our data, DCIS alone can be most accurately measured using mammography. Mammography and MRI show no significant variations from the mean tumour size compared to histology.

4. ILC is measured most accurately using MRI and mammography, provided that the results are visible with mammography. Sonography leads to a significant underestimation of the mean tumour size.

From these results, we conclude that for surgical planning, the histological subtype should be included in the imaging interpretation in order to estimate the tumour size as accurately as possible.

\section{Abbreviations}

ACR: American College of Radiology; BI-RADS: Breast Imaging Reporting and Data System; DCIS: Ductal carcinoma in situ; IDC: Invasive ductal carcinoma; ILC: Invasive lobular carcinoma; LOA: Limits of agreement; MIP: Maximum intensity projection.

\section{Competing interests}

The authors declare that they have no competing interests.

\section{Authors' contributions}

IG carried out imaging and measurements. MR carried out measurements. KK participated in the design of the study and performed the statistical analysis. AS participated in the histological workup. KS carried out imaging and measurements. AH participated in the design of the study and performed the statistical analysis. DW participated in the study design and its coordination. MH participated in the study design and its coordination, imaging, measurements and surgery. All authors read and approved the final manuscript.

\section{Author details}

${ }^{1}$ Department of Obstetrics and Gynecology, University Hospital of Tuebingen, Calwer Street 7, 72076, Tuebingen, Germany. ${ }^{2}$ Institute of Pathology and Neuropathology, University Hospital of Tuebingen, Liebermeister Street 8, 72079, Tuebingen, Germany. ${ }^{3}$ Department of Radiology, Diagnostic and Interventional Radiology, University Hospital of Tuebingen,

Hoppe-Sailer-Street 3, 72076, Tuebingen, Germany.

Received: 4 September 2012 Accepted: 30 June 2013

Published: 5 July 2013

\section{References}

1. American College of Radiology (ACR): Breast Imaging Reporting and Data System Altlas (BI-RADS Atlas). 4th edition. Reston, VA 20191, USA; 2003.

2. Madjar H, Ohlinger R, Mundinger A, Watermann D, Frenz JP, Bader W, Schulz-Wendtland R, Degenhardt F: BIRADS-Analogue Degum Criteria for Findings in Breast Ultrasound - Consensus of the DEGUM Committee on Breast Ultrasound. Ultraschall in Med 2006, 27:374-379.

3. Hieken TJ, Harrison J, Herreros J, Velasco JM: Correlating sonography, mammography, and pathology in the assessment of breast cancer size. Am J Surg 2001, 182:351-354.

4. Shoma A, Moutamed A, Ameen M, Abdelwahab A: Ultrasound for accurate measurement of invasive breast cancer tumor size. Breast J 2006, $12: 252-256$
5. Bosch AM, Kessels AG, Beets GL, Rupa JD, Koster D, van Engelshoven JM, von Meyenfeldt MF: Preoperative estimation of the pathological breast tumour size by physical examination, mammography and ultrasound: a prospective study on 105 invasive tumours. Eur J Radiol 2003, 48:285-292.

6. Onesti JK, Mangus BE, Helmer SD, Osland JS: Breast cancer tumor size: correlation between magnetic resonance imaging and pathology measurements. Am J Surg 2008, 196:844-848. discussion 849-850.

7. Wasif N, Garreau J, Terando A, Kirsch D, Mund DF, Giuliano AE: MRI versus ultrasonography and mammography for preoperative assessment of breast cancer. Am Surg 2009, 75:970-975.

8. Davis PL, Staiger MJ, Harris KB, Ganott MA, Klementaviciene J, McCarty KS Jr, Tobon: Breast cancer measurements with magnetic resonance imaging, ultrasonography, and mammography. Breast Cancer Res Treat 1996, 37:1-9.

9. Boetes C, Mus RD, Holland R, Barentsz JO, Strijk SP, Wobbes T, Hendriks JH, Ruys: Breast tumors: comparative accuracy of MR imaging relative to mammography and US for demonstrating extent. Radiology 1995, 197:743-747.

10. Pritt B, Ashikaga T, Oppenheimer RG, Weaver DL: Influence of breast cancer histology on the relationship between ultrasound and pathology tumor size measurements. Mod Pathol 2004, 17:905-910.

11. Skaane P, Skjorten F: Ultrasonographic evaluation of invasive lobular carcinoma. Act Radiol 1999, 40:369-375.

12. Rodenko GN, Harms SE, Pruneda JM, Farrell RS Jr, Evans WP, Copit DS, Krakos PA, Flamig DP: MR imaging in the management before surgery of lobular carcinoma of the breast: correlation with pathology. Am J Roentgenol 1996, 167:1415-1419.

13. Kolb TM, Lichy J, Newhouse JH: Comparison of the performance of screening mammography, physical examination, and breast US and evaluation of factors that influence them: an analysis of 27,825 patient evaluations. Radiology 2002, 225:165-175.

14. Sardanelli F, Giuseppetti GM, Panizza P, Bazzocchi M, Fausto A, Simonetti G, Lattanzio $V$, Del Maschio A: Sensitivity of MRI versus mammography for detecting foci of multifocal, multicentric breast cancer in fatty and dense breasts using the whole breast pathologic examination as a gold standard. AJR Am J Roentgenol 2004, 183:1149-1157.

15. Mandelson MT, Oestreicher N, Porter PL, White D, Finder CA, Taplin SH, White E: Breast density as a predictor of mammographic detection: comparison of interval-and screen-detected cancers. J Natl Cancer Inst 2000, 92:1081-1087.

16. Ikeda DM, Andersson I: Ductal carcinoma in situ: atypical mammographic appearances. Radiology 1989, 172:661-666.

17. Dershaw DD, Abramson A, Kinne DW: Ductal carcinoma in situ: mammographic findings and clinical implications. Radiology 1989, 170:411-415.

18. Stomper PC, Margolin FR: Ductal carcinoma in situ: the mammographer's perspective. AJR Am J Roentgenol 1994, 162:585-591.

19. Kopans DB, Meyer JE, Lindfers KK: Whole-breast US imaging: four-year follow-up. Radiology 1985, 157:505-507.

20. Yang WT, Tse GM: Sonographic, mammographic, and histopathologic correlation of symptomatic ductal carcinoma in situ. AJR Am J Roentgenol 2004, 182:101-110.

21. Soo MS, Baker JA, Rosen EL: Sonographic detection and sonographically guided biopsy of breast microcalcifications. AJR Am J Roentgenol 2003, 180:941-948.

22. Butler RS, Venta LA, Wiley EL, Ellis RL, Dempsey PJ, Rubin E: Sonographic evaluation of infiltrating lobular carcinoma. AJR Am J Roentgenol 1999, 172:325-330.

23. Lenz $\mathrm{S}$ : Breast ultrasound in office gynecology--ten years of experience. Ultraschall Med 2011, 32(Suppl 1):3-7.

24. Varga D, Woeckel A, Wagner J, Koretz K, Kreienberg R, Sauer G: Value of ultrasound in preoperative local staging in early breast cancer. Ultraschall Med 2011, 32:387-392.

25. Madjar H, Sauerbrei W, Hansen L: Multivariate analysis of flow data in breast lesions and validation in a normal clinical setting. Ultraschall Med 2011, 32:511-517.

26. Ohlinger R, Frese H, Paepke S, Heyer H, Köhler G, Schwesinger G, Grunwald S: Ultrasonographic: compared to histologic sizing of benign and malignant breast Lesions. Geburtsh Frauenheilk 2006, 66:373-376.

27. Isermann R, Grunwald S, Hatzung G, Könsgen-Mustea D, Behrndt PO, Geaid AA, Jäger B, Ohlinger R: Breast Lesion Sizing by B-Mode Imaging and sonoelastography in Comparison to Histopathological Sizing - a prospective study. Ultraschall Med 2011, 32:21-26. 
28. Hahn M, Roessner L, Krainick-Strobel U, Gruber IV, Krämer B, Gall C, Siegmann KC, Wallwiener D, Kagan KO: Sonographic Criteria for the Differentiation of Benign and Malignant Breast Lesions using Real-Time Spatial Compound Imaging in Combination with XRES Adaptive Image Processing. Ultraschall Med 2012, 33:270-274.

29. Berg WA, Gutierrez L, NessAiver MS, Carter WB, Bhargavan M, Lewis RS, loffe OB: Diagnostic accuracy of mammography, clinical examination, US, and MR imaging in preoperative assessment of breast cancer. Radiology 2004, 233:830-849.

30. Kuhl CK, Schrading S, Bieling HB, Wardelmann E, Leutner CC, Koenig R, Kuhn W, Schild HH: MRI for diagnosis of pure ductal carcinoma in situ: a prospective observational study. Lancet 2007, 370:485-492.

31. Schelfout K, Van Goethem M, Kersschot $E$, et al: Preoperative breast MRI in patients with invasive lobular breast cancer. Eur Radiol 2004, 14:1209-1216.

32. Weinstein $S P$, Orel SG, Heller $R$, et al: MR imaging of the breast in patients with invasive lobular carcinoma. AJR Am J Roentgenol 2001, 176(2):399-406.

doi:10.1186/1471-2407-13-328

Cite this article as: Gruber et al:: Measurement of tumour size with mammography, sonography and magnetic resonance imaging as compared to histological tumour size in primary breast cancer. BMC Cancer 2013 13:328.

\section{Submit your next manuscript to BioMed Central and take full advantage of:}

- Convenient online submission

- Thorough peer review

- No space constraints or color figure charges

- Immediate publication on acceptance

- Inclusion in PubMed, CAS, Scopus and Google Scholar

- Research which is freely available for redistribution 